\title{
Specific Targeting of the Basolateral Amygdala to Projectionally Defined Pyramidal Neurons in Prelimbic and Infralimbic Cortex ${ }^{1,2,3}$
}

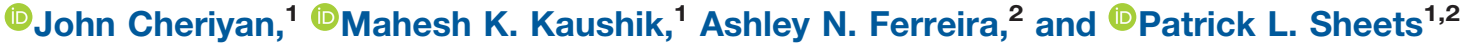

DOI:http://dx.doi.org/10.1523/ENEURO.0002-16.2016

${ }^{1}$ Department of Pharmacology and Toxicology, Indiana University School of Medicine-South Bend, South Bend, Indiana 46617, and ${ }^{2}$ Department of Biological Sciences, University of Notre Dame, Notre Dame, Indiana 46556

\begin{abstract}
Adjacent prelimbic (PL) and infralimbic (IL) regions in the medial prefrontal cortex have distinct roles in emotional learning. A complete mechanistic understanding underlying this dichotomy remains unclear. Here we explored targeting of specific PL and IL neurons by the basolateral amygdala (BLA), a limbic structure pivotal in pain and fear processing. In mice, we used retrograde labeling, brain-slice recordings, and adenoviral optogenetics to dissect connectivity of ascending BLA input onto PL and IL neurons projecting to the periaqueductal gray (PAG) or the amygdala. We found differential targeting of BLA projections to PL and IL cortex. Activating BLA projections evoked excitatory and inhibitory responses in cortico-PAG (CP) neurons in layer 5 (L5) of both PL and IL cortex. However, all inhibitory responses were polysynaptic and monosynaptic BLA input was stronger to CP neurons in IL cortex. Conversely, the BLA preferentially targeted corticoamygdalar (CA) neurons in layer 2 (L2) of PL over IL cortex. We also reveal that BLA input is projection specific by showing preferential targeting of L5 CP neurons over neighboring L3/5 CA neurons in IL cortex. We conclude by showing that BLA input is laminar-specific by producing stronger excitatory responses CA neurons in L3/5 compared with L2 in IL cortex. Collectively, this study reveals differential targeting of the BLA to PL and IL cortex, which depends both on laminar location and projection target of cortical neurons. Overall, our findings should have important implications for understanding the processing of pain and fear input by the PL and IL cortex.
\end{abstract}

Key words: basolateral amygdala; infralimbic; long-range connectivity; medial prefrontal cortex; periaqueductal gray; prelimbic

\section{Significance Statement}

The prelimbic (PL) and infralimbic (IL) cortices are comprised of a heterogeneous population of pyramidal neurons that receive, integrate, and relay information ascending from subcortical (long-range) origins. For the first time, we address critical unknowns regarding long-range targeting of the basolateral amygdala (BLA) to specific PL and IL neurons projecting to key subcortical structures involved in pain and fear, the periaqueductal gray (PAG), and the amygdala. Our data reveal a distinctive pattern of BLA input to these neurons demonstrating that BLA-mPFC connections are region-, laminar-, and projection-specific. Elucidating the organization and strength of long-range connections to specific neurons in the PL and IL cortex provides valuable insight into cortical processing of outputs relevant in pain and anxiety disorders. 


\section{Introduction}

The prelimbic (PL) and infralimbic (IL) cortex are adjacent regions shown to have distinct roles in integrating sensory and emotional information. A main focus of the PL-IL dichotomy has involved mainly fear behavior. Specifically, the PL cortex is implicated in fear expression (Vidal-Gonzalez et al., 2006; Corcoran and Quirk, 2007; Burgos-Robles et al., 2009; Laurent and Westbrook, 2009; Sierra-Mercado et al., 2011; Fitzgerald et al., 2014), whereas the IL cortex is critical for fear extinction (Milad and Quirk, 2002; Sierra-Mercado et al., 2006; Laurent and Westbrook, 2009; Chang and Maren, 2011; SierraMercado et al., 2011; Holmes et al., 2012; Do-Monte et al., 2015). Distinct subpopulations of neurons in the basolateral amygdala (BLA) target the PL and IL cortex and display increased firing associated with fear conditioning and fear extinction, respectively (Senn et al., 2014). Long-range input from ascending BLA projections excites pyramidal neurons in layer 2 (L2) of the medial prefrontal cortex (mPFC; Little and Carter, 2012) preferentially targeting neurons with projections returning to the BLA (Little and Carter, 2013). However, the differential laminar targeting and connectivity of BLA inputs to specific $\mathrm{PL}$ and IL neurons identified by subcortical projection target has not been studied.

For this study, we were interested in dissecting BLA targeting of projectionally defined pyramidal neurons in $L 2$ and $L 5$ in both the PL and IL cortex. A major subcortical target of $\mathrm{L} 5$ neurons in the MPFC is the periaqueductal gray (PAG; Ferreira et al., 2015). The PAG is a key midbrain structure within a network responsible for regulating multiple physiological responses, most notably descending inhibition of ascending nociceptive input (Basbaum and Fields, 1978; Behbehani, 1995). Studies show that the BLA evokes excitatory responses in pyramidal neurons in L5 of the mPFC (Ishikawa and Nakamura, 2003; OrozcoCabal et al., 2006). Therefore, BLA is poised to have significant effects on descending pain regulation via input onto L5 cortico-PAG (CP) neurons in the MPFC.

Another major projection target of the mPFC is the amygdala (Hurley et al., 1991; Brinley-Reed et al., 1995; McDonald, 1998). Previous studies show that PL and IL connect to different regions of the amygdala with $\mathrm{PL}$

Received January 4, 2016; accepted February 15, 2016; First published March 12, 2016.

${ }^{1}$ The authors declare no competing financial interests.

${ }^{2}$ Author contributions: J.C., M.K.K., and A.N.F. performed research; J.C. and P.L.S. analyzed data; P.L.S. designed research; J.C. and P.L.S. wrote the paper.

${ }^{3}$ The work was supported by National Institutes of Health Grant R01NS094389 (P.L.S.) and the Navari Family Foundation (P.L.S.). We thank Hanna Yousuf and Patrick E. Monahan for support with experiments and data analysis, and Alfonso Jr, Apicella (University of Texas at San Antonio) for feedback on the experiments and artistic contributions.

Correspondence should be addressed to Dr. Patrick L. Sheets, Indiana University School of Medicine-South Bend, Raclin-Carmichael Hall, Room 127, 1234 Notre Dame Avenue, South Bend, IN 46617. E-mail: plsheets@iupui.edu. DOI:http://dx.doi.org/10.1523/ENEURO.0002-16.2016

Copyright (C) 2016 Cheriyan et al.

This is an open-access article distributed under the terms of the Creative Commons Attribution 4.0 International, which permits unrestricted use, distribution and reproduction in any medium provided that the original work is properly attributed. targeting the basolateral nuclei (Vertes, 2004; Gabbott et al., 2005) and IL targeting GABAergic central nucleus and intercalated cells (McDonald et al., 1996; Berretta et al., 2005; Amir et al., 2011). This has offered one mechanistic explanation for PL-IL dichotomy in fear conditioning paradigms (Peters et al., 2009). Yet, differential targeting of the BLA to corticoamygdalar (CA) neurons in $\mathrm{PL}$ versus IL is likely another contributing factor to this dichotomy.

Here we aimed to determine: (1) whether the BLA makes long-range connections to L5 CP neurons in MPFC and (2) whether the synaptic connectivity of the BLA to CP and $C A$ neurons was different between $P L$ and $I L$ cortices of the MPFC. Using optogenetics and retrograde labeling, we show that the BLA differentially targets $\mathrm{CP}$ and CA neurons in PL versus IL and that this targeting depends on laminar location and projection target of the output neuron.

\section{Materials and Methods}

\section{Animals}

Wild-type C57BI/6J mice (Harlan Laboratories; total: $n$ $=66$ ) of either gender (35-46 d old) were used in accordance with the animal care and use guidelines of Indiana University, The University of Notre Dame, and the National Institutes of Health.

\section{Surgical procedure for intracranial injections}

Mice were anesthetized with $1.5 \%$ isoflurane in $100 \%$ $\mathrm{O}_{2}$ with a flow rate of $0.6 \mathrm{~L} / \mathrm{min}$ (SurgiVet Isotech 4, Smith). Body temperature was maintained at $37^{\circ} \mathrm{C}$ using a feedback-controlled heating pad. The head was mounted in a stereotaxic frame (900 series, Kopf Instruments) and buprenorphine $(0.03 \mathrm{mg} / \mathrm{kg})$ was injected subcutaneously prior to the surgical procedure. The top of the head was shaved and betadine was used to disinfect the area. A midline incision was made to the scalp to expose the skull. For PAG and BLA injections, the scalp was incised, a craniotomy was made, the dura was reflected, and pipettes were advanced to reach the stereotaxic coordinates of the desired target. Following surgery, meloxicam $(0.25 \mathrm{mg} / \mathrm{kg})$ was injected subcutaneously for pain relief during recovery.

\section{Retrograde tracer and adenoviral injections}

Tracer and virus injections were performed using a Hamilton syringe connected to a UltraMicoPump 3 driven by a Micro 4 MicroSyringe Pump Controller (World Precision Instruments). Retrograde tracers were either cholera toxin $\beta$-subunits conjugated with AlexaFluor 647 dye (Life Technologies) or fluorescent red Retrobeads IX (Lumafluor). Submicroliter volumes $(\sim 100-200 \mathrm{nl})$ of retrograde tracer were injected at a rate of $100 \mathrm{nl} / \mathrm{min}$. For anterograde expression of channelrhodopsin-2 (ChR2) recombinant adeno-associated virus AAV1.CAG.ChR2-Venus.WPRE.SV40 (Petreanu et al., 2007, 2009) was injected $(50-100 \mathrm{nl})$ at a rate of 100 $\mathrm{nl} / \mathrm{min}$. The virus was purchased through the UPenn Vector Core (Addgene 20071). Stereotaxic coordinates for PAG injections were as follows (in $\mathrm{mm}$ relative to bregma): 3.4 caudal, 0.5 lateral, and 2.8-3.2 deep at a $0^{\circ}$ angle off the 
vertical plane. For BLA injections, coordinates were as follows (in $\mathrm{mm}$ relative to bregma): 0.73 caudal, 3.4 lateral, and 4.6 deep at a $4^{\circ}$ angle off the vertical plane.

\section{Slice preparation}

Brain slices were prepared as previously described (Sheets et al., 2011; Ferreira et al., 2015) at postnatal days 35-46 (ie, 14-21 d after AAV-ChR2 injections). Modified coronal brain sections (spine of the blade tilted rostrally 15-25ㅇ $300 \mu \mathrm{m}$ thick) containing mPFC were made by vibratome-sectioning the brain (VT1200S, Leica) in icecold cutting solution [composed of the following (in $\mathrm{mm}$ ): 110 choline chloride, $25 \mathrm{NaHCO}_{3}, 25$ D-glucose, 11.6 sodium ascorbate, $7 \mathrm{MgSO}_{4}, 3.1$ sodium pyruvate, 2.5 $\mathrm{KCl}, 1.25 \mathrm{NaH}_{2} \mathrm{PO}_{4}$, and $0.5 \mathrm{CaCl}_{2}$ ]. Slices were transferred to artificial CSF [ACSF; composed of the following (in mM): $127 \mathrm{NaCl}, 25 \mathrm{NaHCO}_{3}, 25 \mathrm{D}$-glucose, $2.5 \mathrm{KCl}, 1$ $\mathrm{MgCl}_{2}, 2 \mathrm{CaCl}_{2}$, and $1.25 \mathrm{NaH}_{2} \mathrm{PO}_{4}$, aerated with $95 \%$ $\mathrm{O}_{2}, 5 \% \mathrm{CO}_{2}$ ] at $37^{\circ} \mathrm{C}$ for $30 \mathrm{~min}$. Slices were subsequently incubated in ACSF at $22^{\circ} \mathrm{C}$ for at least $1 \mathrm{~h}$ prior to electrophysiological and optogenetic experiments.

\section{Fluorescence imaging and analysis}

Acute cortical slices were visualized under coolLED optics (Scientifica) and fluorescence intensity analyses were performed using custom routines in MATLAB (MathWorks). Images were rotated to align the pia horizontally and regions of interest spanning the entire cortical thickness and containing labeled axons in the PL cortex and IL cortex were selected. The pixel intensities in these regions-of-interest were averaged along the rows, yielding a profile representing the average pixel intensities along the medial-lateral axis, showing the radial distribution of YFP fluorescence in the mPFC. Next, we performed background subtraction to reduce the autofluorescence signal, by fitting a polynomial to the nonfluorescent portions of the profile and subtracting a calculated background profile from the raw profile.

\section{Optogenetic and electrophysiological recordings}

Briefly, slices were transferred to the recording chamber of an upright microscope (BX51, Olympus), and held in place with short pieces of flattened gold wire $(0.813 \mathrm{~mm}$ diameter; Alfa Aesar). Fluorescently labeled neurons were visualized using coolLED optics (Scientifica). Pipettes for whole-cell recordings were fabricated from borosilicate capillaries with filaments (G150-F, Warner) using a horizontal puller (P-97, Sutter), and filled with intracellular solution composed of the following (in $\mathrm{mm}$ ): $128 \mathrm{Cs}-$ methanesulfonate, 10 HEPES, 1 EGTA, $4 \mathrm{MgCl}_{2}$, 4 ATP, and 0.4 GTP, 10 phosphocreatine, 3 ascorbate, and 0.05 AlexaFluor 594 or 488 (Molecular Probes), pH 7.3. EGTA was included both to facilitate seal formation and to reduce cytosolic calcium elevations induced by the various stimulus protocols used in these studies. ACSF was used as the extracellular recording solution. Recordings were targeted to retrogradely labeled pyramidal neurons 60$100 \mu \mathrm{m}$ deep in the slice. Pipette capacitance was compensated; series resistance was monitored but not compensated, and required to be $<35 \mathrm{M} \Omega$ for inclusion in the dataset. Recordings were filtered at $4 \mathrm{kHz}$ and digi- tized at $10 \mathrm{kHz}$. Slices were ideally used $1.5-3 \mathrm{~h}$ after preparation, but some were used up to $6 \mathrm{~h}$ after preparation. Recordings were performed at $34^{\circ} \mathrm{C}$. The ACSF was refreshed every $2 \mathrm{~h}$. The recording temperature was controlled by an in-line heating system (TC324B, Warner). In voltage clamp configuration, excitatory (glutamatergic) and inhibitory (GABAergic) responses during photoactivation of ChR2-positive BLA projections were recorded at command voltages of $-70 \mathrm{mV}$ and $+10 \mathrm{mV}$, respectively. Wide-field photoactivation (40 mW, $3 \mathrm{~ms}$ ) of ChR2positive BLA axons was performed using a $470 \mathrm{~nm}$ wavelength LED (CoolLED pE excitation system) in line with a GFP filter (ET FITC/GFP, Olympus) and a $4 \times$ objective. For monosynaptic recordings, application of TTX $(0.5 \mu \mathrm{M})$ and CPP $(5 \mu \mathrm{M})$ was added to eliminate polysynaptic and NMDAR activity, respectively, and 4-AP (0.1 mm) was added to restore glutamate release (Petreanu et al., 2009; Little and Carter, 2012, 2013). Paired comparisons of monosynaptic strength were done in sequential recordings of labeled neurons within the same brain slice to limit variability due to AAV infection variability and/or slice orientation. The order of recorded neurons was alternated between slices.

\section{Glutamate uncaging and laser scanning photostimulation}

Glutamate uncaging and laser scanning photostimulation (glu-LSPS) were performed using an ultraviolet (UV) laser (355 nm; DPSS Lasers). Stock solutions of MNIcaged glutamate (50 $\mathrm{mm}$ in water) were prepared at room temperature (to avoid precipitation) with sonication, aliquoted, and stored at $-20^{\circ} \mathrm{C}$ until use. Ephus software was used for hardware control and data acquisition (http://www.ephus.org; Suter et al. 2010). The bath solution for photostimulation studies contained elevated concentrations of divalent cations ( $4 \mathrm{mM} \mathrm{Ca}^{2+}$ and $4 \mathrm{mM} \mathrm{Mg}^{2+}$ ) and an NMDA receptor antagonist (5 $\mu \mathrm{M}$ CPP; Tocris Bioscience), to dampen neuronal excitability. Caged glutamate (0.2 mM; MNI-glutamate, Tocris Bioscience) was added to the bath solution. Voltages were not corrected for liquid junction potential. Recordings were performed at $21^{\circ} \mathrm{C}$ and were monitored for series resistance (inclusion criterion: $<40$ $\mathrm{M} \Omega$; mean: $\sim 25 \mathrm{M} \Omega$ ). For excitatory recordings, patch pipettes contained potassium-based intracellular solution (in mM: 128 K-gluconate, 10 HEPES, 1 EGTA, $4 \mathrm{MgCl}_{2}$, 4 ATP, and 0.4 GTP, 10 phosphocreatine, 3 ascorbate, and 0.05 AlexaFluor 594 or 488 hydrazide). For inhibitory recordings, equimolar cesium was substituted for potassium, and $1 \mathrm{~mm}$ QX-314 was added to the intracellular solution. Photostimulation sites resulting in activation of glutamate receptors in the membrane of the recorded neuron were readily detected based on characteristically short onset latencies $(<7 \mathrm{~ms})$ of responses (Schubert et al., 2001; Anderson et al., 2010), and excluded from analysis. All remaining recorded inputs with onset latencies greater than $7 \mathrm{~ms}$ were included in the map analysis as synaptic responses resulting from uncaged glutamate activation of presynaptic neurons within the local circuit. Excitatory (glutamatergic) responses were recorded at a command voltage of $-70 \mathrm{mV}$. Excitatory input maps (see Fig. 3) were constructed on the basis of the mean 
Table 1. Statistical tests

\begin{tabular}{llllll}
\hline & Data & Test & Data & Power, \% & Effect size \\
a & Unknown & Paired $t$ test & IL-CP excitatory & 14.3 & 0.33 \\
b & Normal & Paired $t$ test & IL-CP inhibitory & 97.3 & 1.62 \\
c & Normal & Paired $t$ test & PL-CP excitatory & 77.9 & 0.97 \\
d & Normal & Paired $t$ test & PL-CP inhibitory & 98.9 & 1.52 \\
e & Normal & Unpaired $t$ test & PL-CP vs IL-CP & 91.8 & 1.45 \\
f & Unknown & Paired $t$ test & PL-CP vs IL-CP & 77.2 & 1.03 \\
g & Normal & Paired $t$ test & PL-CA vs IL-CA & 67.6 & 1.09 \\
h & Unknown & Paired $t$ test & IL-CP vs IL-CA & 63.6 & 1.04 \\
i & Normal & Paired $t$ test & L2 vs L5 IL-CA & 89.4 & 1.33
\end{tabular}

Data normality was determined using a Lilliefors test. Nonparametric statistical analysis produced similar results. Post hoc power analysis was performed using G*Power 3(v3.1.9.2, www.Gpower.hhu.de; Faul et al., 2007).

inward current over a 0-50 ms poststimulus time window. Inhibitory (GABAergic) responses were recorded at a command voltage of $+10 \mathrm{mV}$. Inhibitory input maps were constructed on the basis of the mean outward current over a 0-750 ms poststimulus time window. Animal numbers reported for inhibitory maps are a subset of animals reported for excitatory maps because excitatory and inhibitory maps were acquired in the same recorded neuron. In some cases following acquisition of excitatory input maps, the recording was lost and subsequent inhibitory maps could not be acquired.

\section{Data analysis}

Data acquisition and statistical analysis was performed using MATLAB routines (MathWorks). Data are represented as means with error bars showing the SEM. Group comparisons were performed with the Student's $t$ test (for normally distributed data) or the Wilcoxon rank sum test (for non-normally distributed data). Significance was set at $p<0.05$. Superscript letters listed with $p$-values correspond to the statistical tests shown in Table 1.

\section{Results}

\section{Axons originating in the basolateral amygdala are differentially expressed in PL and IL regions of the mPFC}

Injection of AAV-ChR2-YFP into the BLA ( Fig. 1A,B) resulted in robust labeling of YFP+ BLA axons in the medial prefrontal cortex (mPFC; Fig. 1C,D). However, the coronal expression pattern of BLA axons differed between the PL and IL regions of MPFC (Fig. 1D). Specifically, the fluorescence intensity of BLA axons in L2 was greater in $\mathrm{PL}$ compared to IL, whereas the expression in L5 was observed to be uniform across IL, but was limited in the PL cortex (Fig. 1E,F). This expression pattern indicates that BLA synaptically targets neurons based on both their regional and laminar location within the mPFC and hence could differentially affect local circuit activity within the PL versus the IL cortex.

\section{The BLA differentially targets CP neurons in the PL and IL cortex}

To determine BLA connectivity to CP neurons in $\mathrm{PL}$ and IL cortex, we injected AAV-ChR2-YFP into BLA and retrograde tracer into the PAG (Fig. $2 A, B$ ). Labeled CP neurons were identified in L5 of PL and IL cortex, which over- lapped with the expression of BLA axons (Fig. 2C). Widefield stimulation of BLA axons via $470 \mathrm{~nm}$ LED light elicited both EPSCs and IPSCs in whole-cell recorded IL-CP neurons ( $n=9$ neurons/7 mice; Fig. $2 D, E)$. We added TTX $(0.5 \mu \mathrm{M})$ and CPP $(5 \mu \mathrm{M})$ to eliminate polysynaptic and NMDAR activity, respectively, and added 4-AP $(0.1 \mathrm{~mm})$ to restore glutamate release. Recorded EPSCs (mean of peak $\pm 1 \mathrm{~ms})$ in IL-CP neurons $(401 \pm 154 \mathrm{pA}$ ) decreased only marginally after treatment with blockers (365 $\pm 142 \mathrm{pA} ; p=0.18^{\mathrm{a}}$; Student's paired $t$ test) indicating that BLA axons primarily make monosynaptic excitatory connections onto AMPA receptors in IL-CP neurons (Fig. 2E,F). Recorded IPSCs (peak; $655 \pm 71$ pA) were eliminated by polysynaptic blockers (12.9 $\pm 1.5 \mathrm{pA}$; $p=0.001^{\mathrm{b}}$; Student's paired $t$ test) confirming that BLA inhibition of IL-CP neurons is driven by activation of inhibitory interneurons within the local circuitry of the IL cortex (Fig. 2G). Stimulation of BLA axons also produced both EPSCs $(1200 \pm 314 \mathrm{pA})$ and IPSCs $(1156 \pm 249 \mathrm{pA})$ in PL-CP neurons $(n=10$ neurons/7 mice; Fig. $2 H, l)$. However, addition of polysynaptic blockers significantly reduced BLA-driven EPSCs $\left(291 \pm 76.8 \mathrm{pA} ; p=0.02^{\mathrm{C}}\right)$ and IPSCs $\left(15.3 \pm 4.5 \mathrm{pA} ; p=0.0002^{\mathrm{d}}\right)$ in PL-CP neurons (Fig. 2I-K). Remaining EPSC after blockers suggested that BLA input to PL-CP neurons consists of both polysynaptic and monosynaptic connections.

Overall, we found that percent EPSC remaining (mean of peak $\pm 1 \mathrm{~ms}$ ) following addition of polysynaptic blockers was significantly lower for PL-CP neurons (35.4 \pm $10.6 \%)$ compared with L5 IL-CP neurons $(96.7 \pm 16.4 \%$; $p=0.005$; Student's unpaired $t$ test; Fig. $3 A$ ). Based on this finding, we hypothesized that excitatory monosynaptic input originating in the BLA was stronger to IL-CP neurons compared to PL-CP neurons. In the presence of polysynaptic blockers, we performed sequential recordings from pairs of L5 PL-CP and IL-CP neurons in the same brain slice and measured EPSCs elicited by optogenetic activation of BLA axons (Fig. $3 B$ ). We found that BLA input evoked significantly larger monosynaptic EPSCs in IL-CP neurons $(622 \pm 119 \mathrm{pA})$ compared to PL-CP neurons $\left(44.5 \pm 26.8 \mathrm{pA} ; n=9\right.$ pairs $/ 7$ mice; $p=0.016^{f}$; Student's paired $t$ test Fig. $3 C, D)$. These data demonstrated preferential monosynaptic targeting of BLA input to L5 CP neurons in IL versus PL cortex.

Because wide-field excitation of BLA inputs elicited polysynaptic responses in PL-CP neurons, we used glu- 
A

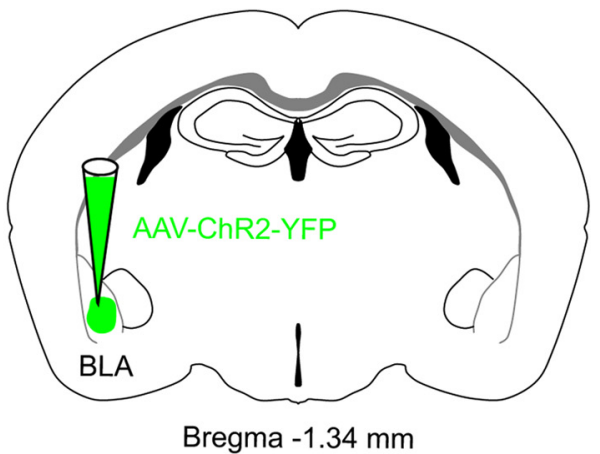

B
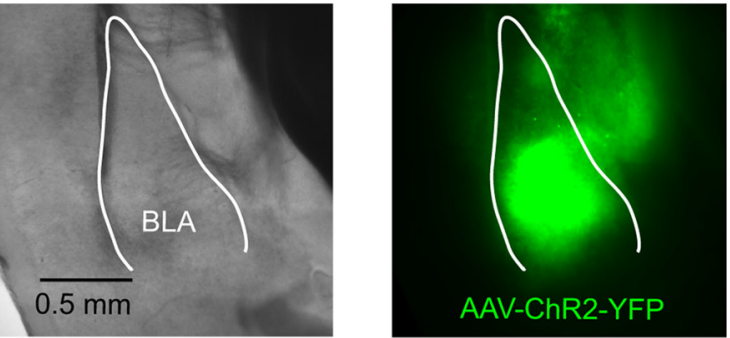

C

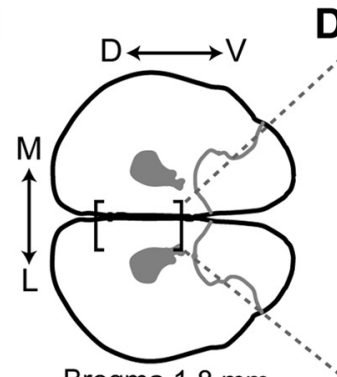

Bregma $1.8 \mathrm{~mm}$

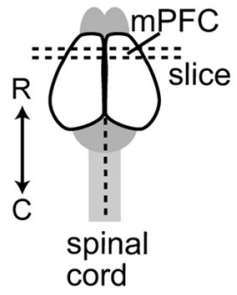

E

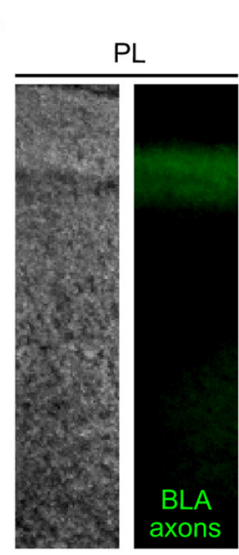

$0.15 \mathrm{~mm}$
D

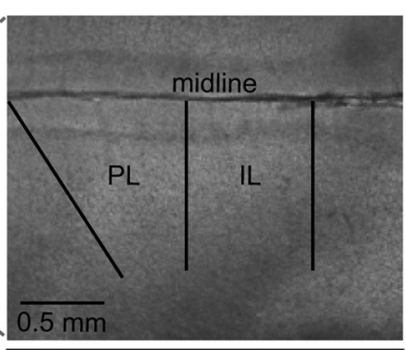

BLA-ChR2-YFP+ axons

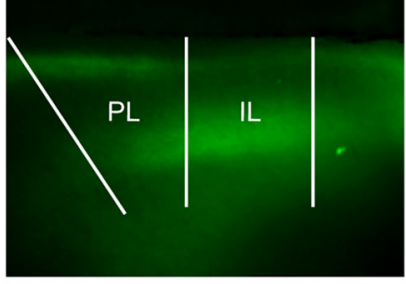

$\mathbf{F}$

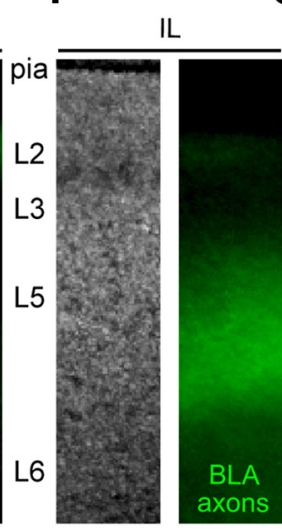

G Fluorescence Pluores

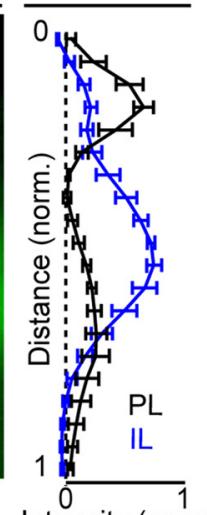

Intensity (norm.)

Figure 1. Expression of BLA axons in PL and IL regions of the

Figure 1. continued

mPFC. $\boldsymbol{A}$, Schematic of AAV-ChR2-YFP injection into the BLA. $\boldsymbol{B}, \mathrm{A}$ representative coronal brain section (left, bright-field; right, epifluorescence) showing AAV-ChR2-YFP injection into the BLA. C, Bottom, Schematic of the rostral-caudal $(R \leftrightarrow C)$ location of coronal slice containing the mPFC. $\boldsymbol{C}$, Top, Schematic of a coronal brain section oriented so that the pia of both the PL and IL cortex was horizontal in the imaging chamber. $\boldsymbol{D}$, A representative image of a coronal brain section containing PL and IL cortex (top, bright-field; bottom, epifluorescence) in which BLA axons were anterogradely labeled with YFP from AAV-ChR2YFP. $\boldsymbol{E}, \boldsymbol{F}$, Bright-field and epifluorescence images showing laminar distribution of BLA expression in PL and IL. $\mathbf{G}$, Normalized fluorescence intensity (mean \pm SEM) of BLA axons $(n=5$; 5 animals) as a function of normalized cortical distance (where pia $=0$ and white matter $=1$ ) in $\mathrm{PL}$ (black) and IL (blue). Dorsal-ventral, $\mathrm{D} \leftrightarrow \mathrm{V}$; lateral-medial, $\mathrm{L} \leftrightarrow \mathrm{M}$.

LSPS to map the local excitatory and inhibitory circuits for PL-CP neurons. Glutamate was "uncaged" via UV stimulation $(20 \mathrm{~mW}, 1 \mathrm{~ms})$ in a $16 \times 16$ grid $(75 \mu \mathrm{m}$ spacing) tangent with the pia and centered horizontally with the PL-CP soma (Fig. 3E). As previously described (Ferreira et al., 2015), responses were recorded in voltage-clamp mode ( $-70 \mathrm{mV}$ : excitatory; $+10 \mathrm{mV}$ : inhibitory; Fig. $3 F)$ to produce a trace map of input from local presynaptic locations which we converted to color maps for visualization. Input maps ( $n=22$ neurons/14 mice) showed that PL-CP neurons receive strong local excitatory and inhibitory input from L2 (Fig. 3F-H). Local inhibitory maps also show robust IPSCs in PL-CP neurons following perisomatic activation of L5 neurons (Fig. $3 H$ ). It has been previously shown that IL-CP neurons also receive strong local excitatory and inhibitory input from L2 (Ferreira et al., 2015). However, BLA axon expression is low in L2 of IL (Fig. 1D) and stimulation of BLA input produced mainly monosynaptic EPSCs in IL-CP neurons (Fig. 2F). This suggests that BLA evoked responses in IL-CP neurons does not involve the activation of a local L2 $\rightarrow$ L5 pathway.

We postulated that the strong polysynaptic and monosynaptic input to PL-CP and IL-CP neurons, respectively, is, at least in part, due to differences in the targeting of the BLA to $L 2$ in PL and IL cortex. A major class of L2 output neurons in the MPFC is CA neurons (Little and Carter, 2013; Ferreira et al., 2015). We next coinjected retrograde tracer and AAV-ChR2-YFP into the BLA and measured the strength of monosynaptic BLA input in sequential recordings of L2 PL-CA and IL-CA neurons (Fig. 3l,J). Activation of BLA input evoked significantly larger EPSCs (mean of peak $\pm 1 \mathrm{~ms})$ in L2 PL-CA neurons $(251.6 \pm 78$ pA) compared with L2 IL-CA neurons $(35.4 \pm 6.5 \mathrm{pA} ; n=$ 7 pairs $/ 6$ mice; $p=0.04^{\mathrm{g}}$; Fig. $\left.3 K, L\right)$. This is consistent with the stronger BLA axonal expression seen in L2 of PL cortex over IL cortex (Fig. 1). Previous work has shown that the BLA can drive action potential firing of CA neurons in L2 of the mPFC (Little and Carter, 2013). Given the robust BLA axon expression in L2 of $\mathrm{PL}$, we tested whether optogenetic stimulation of BLA inputs was sufficient to drive firing in retrogradely labeled $L 2$ CA neurons in PL. Performing cell-attached recordings in current- 


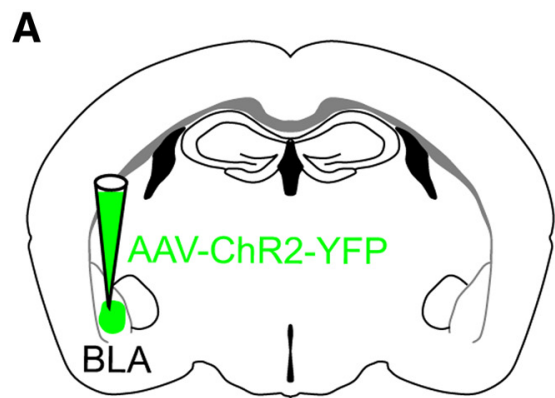

Bregma - $1.34 \mathrm{~mm}$
B

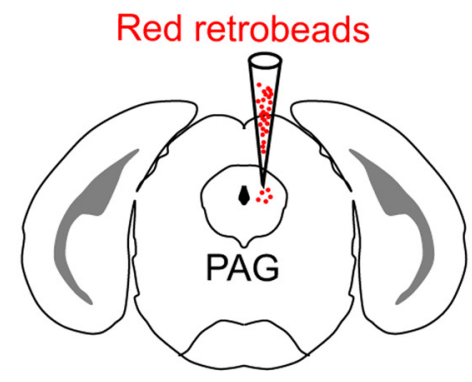

Bregma - $4.3 \mathrm{~mm}$
C

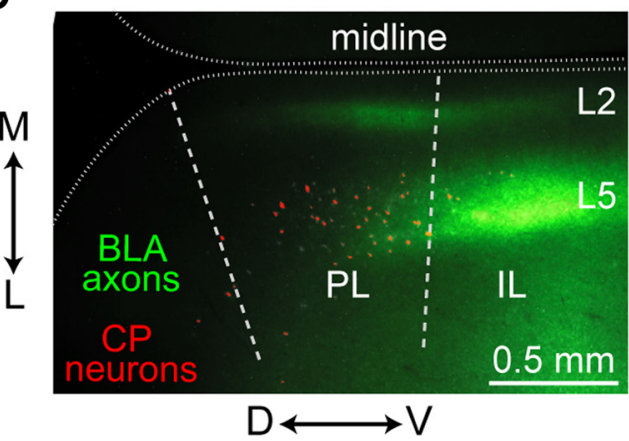

D

mPFC slice

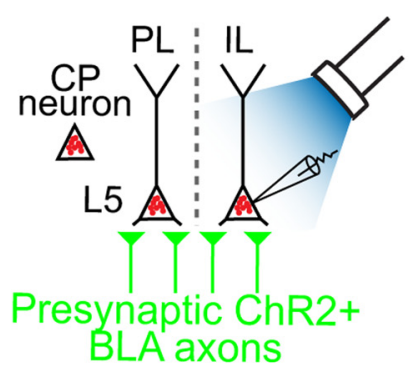

E

$$
\mathrm{BLA} \rightarrow \mathrm{IL}-\mathrm{CP} \text { neuron }
$$

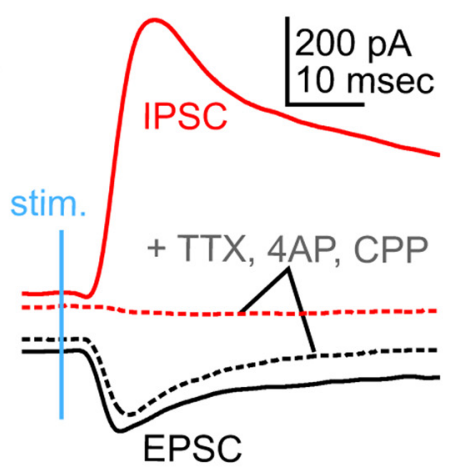

H

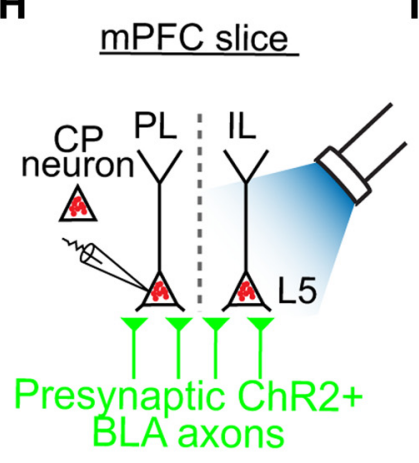

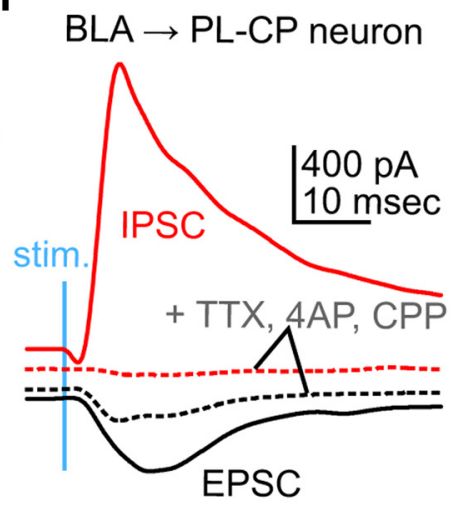

$\mathbf{F}$

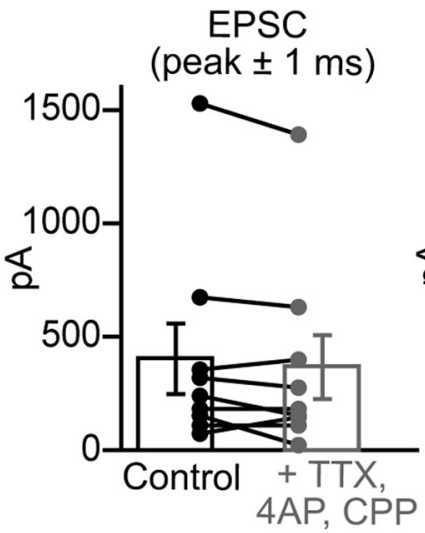

G

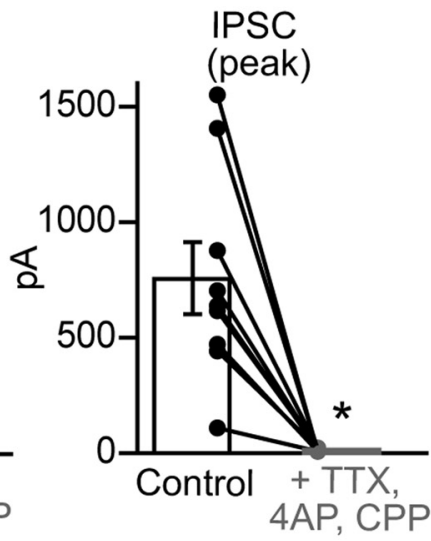

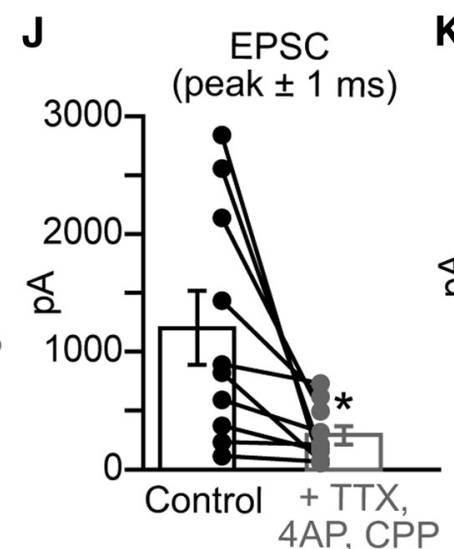

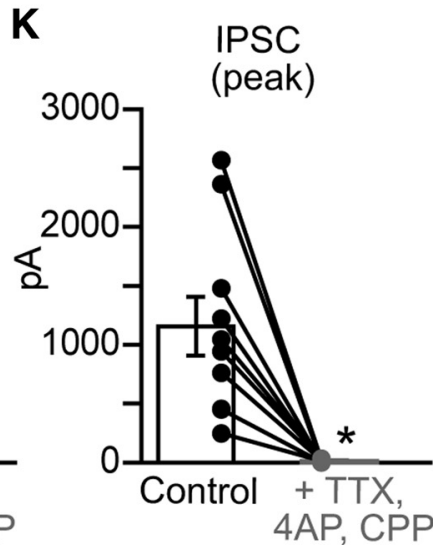

Figure 2. $\mathrm{CP}$ neurons in $\mathrm{L} 5$ of the $\mathrm{PL}$ and IL cortex receive monosynaptic and polysynaptic input from the BLA. $\boldsymbol{A}$, Injection of AAV-ChR2-YFP into the BLA. B, Injection of retrograde tracer into the PAG. $\boldsymbol{C}$, Epifluorescence image overlay of brain slice showing regional and laminar distribution of YFP positive BLA axons (green) and red beads illuminated CP neurons (red) in the PL and IL cortical regions (outlined with dotted lines). Layers 2 and 5 are marked as L2 and L5, respectively (dorsal-ventral, D $\leftrightarrow \mathrm{V}$; lateral-medial, $\mathrm{L} \leftrightarrow \mathrm{M})$. $\boldsymbol{D}$, Schematic showing how synaptic input was measured in whole-cell recordings of retrogradely labeled L5 CP neurons in IL cortex during wide-field activation of ChR2 + BLA axons via blue LED stimulation. $E$, Examples of EPSC (black trace; holding at $-70 \mathrm{mV}$ ) and IPSC (red trace; holding at $+10 \mathrm{mV}$ ) recorded from L5 IL-CP neurons before and after addition of polysynaptic blockers (TTX $0.5 \mu \mathrm{M}, 4-\mathrm{AP} 0.1 \mathrm{~mm}$, CPP $5 \mu \mathrm{M}$ : dashed traces). $\boldsymbol{F}$, Paired comparison of recorded EPSC values in IL-CP neurons before (black) and after addition of polysynaptic blockers (gray). G, Paired comparison of recorded IPSC values for IL-CP neurons before (black) and after addition of polysynaptic blockers (gray). $\boldsymbol{H}$, Schematic showing how synaptic input was measured in whole-cell recordings of retrogradely labeled L5 CP neurons in PL cortex during wide-field activation of ChR2 + BLA axons via blue LED stimulation. $\boldsymbol{I}$, Examples of a BLA evoked EPSC (black trace; holding at $-70 \mathrm{mV}$ ) and IPSC (red trace; holding at $+10 \mathrm{mV}$ ) recorded from L5 PL-CP neurons before and after addition of polysynaptic blockers (TTX $0.5 \mu \mathrm{M}, 4-\mathrm{AP} 0.1 \mathrm{~mm}, \mathrm{CPP} 5 \mu \mathrm{M}$ : dashed traces). J, K, Paired comparison showing a significant decrease in BLA evoked EPSCs and IPSCs recorded from PL-CP neurons after addition of polysynaptic blockers. $*=\mathrm{p}<0.05$; error bars $=$ SEM. 
A

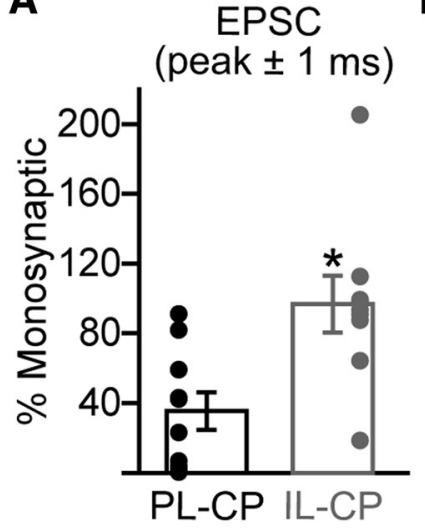

E

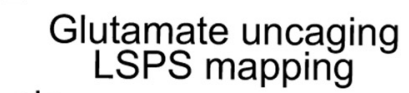

pia LSPS mapping

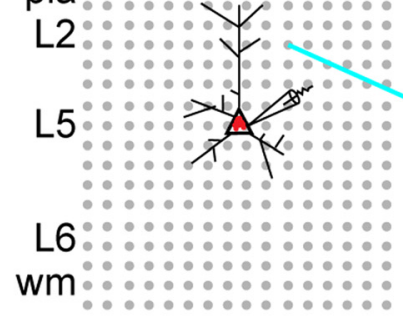

PL-CP neuron
B

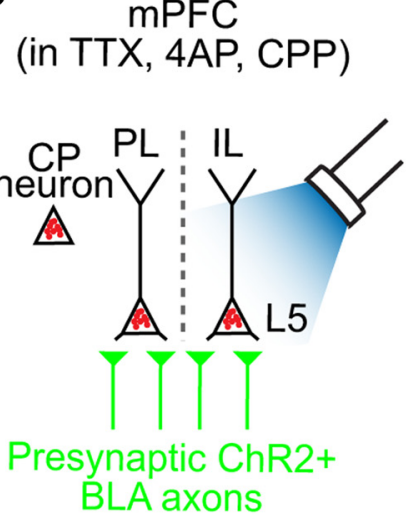

F
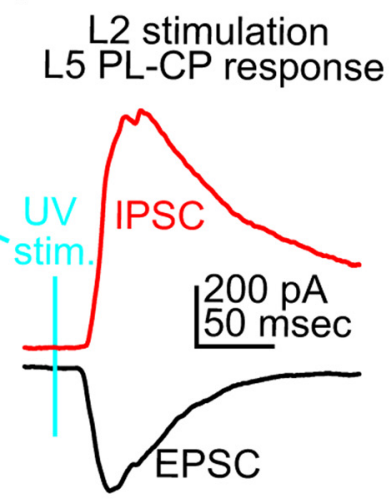

C

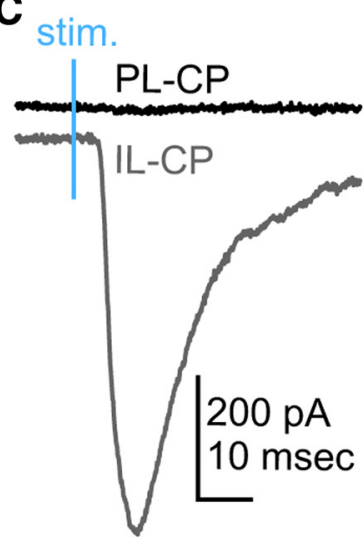

G

\section{Excitatory local circuit map}

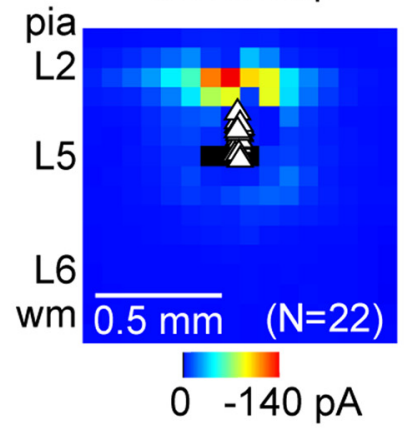

D

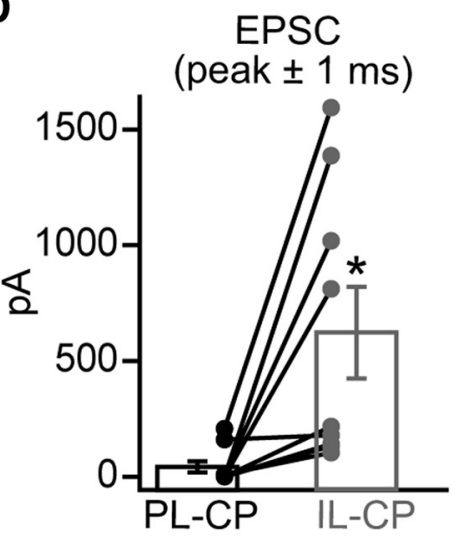

H
Inhibitory local circuit map

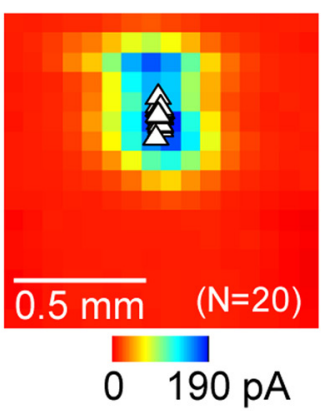

I

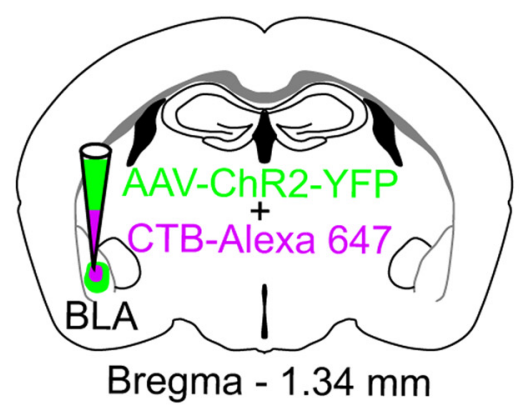

J

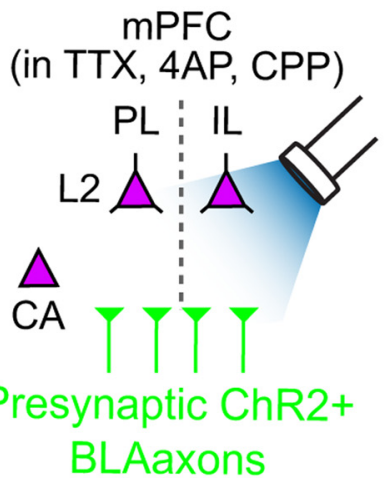

K

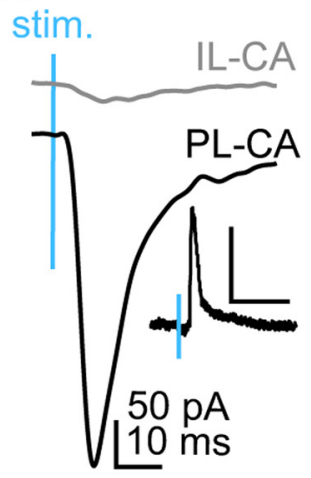

L

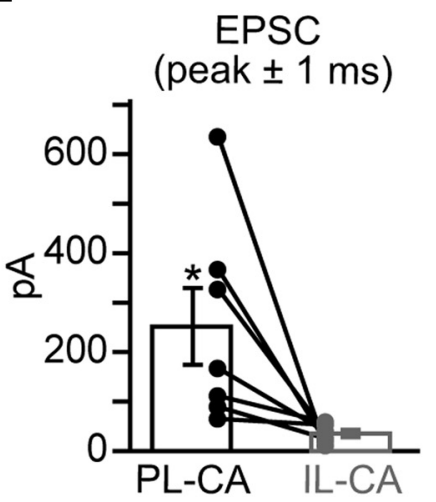

Figure 3. The BLA differentially targets CP neurons in PL and IL cortex. $\boldsymbol{A}$, Comparison of the percentage EPSC (peak \pm 1 ms) remaining following application of polysynaptic blockers for PL-CP and IL-CP neurons. $\boldsymbol{B}$, Experimental paradigm for comparing monosynaptic input (in TTX, 4AP, CPP) to retrogradely labeled L5 CP neurons in PL and IL during wide-field activation of ChR2+ BLA axons via blue LED stimulation. C, Examples of monosynaptic EPSCs for a PL-CP neuron (black trace) and IL-CP neuron (gray trace) in the same slice following blue LED stimulation (stim) of ChR2 + BLA axons. D, Paired comparison of EPSC values for PL-CP and IL-CP neurons. $\boldsymbol{E}$, Schematic representation for the $16 \times 16$ stimulation grid (75 $\mu \mathrm{m}$ spacing) using for local circuit mapping of retrogradely labeled PL-CP neurons using UV-assisted glutamate uncaging (L, layer; wm, white matter). $\boldsymbol{F}$, Examples of an EPSC (black trace; holding at $-70 \mathrm{mV}$ ) and an IPSC (red trace; holding at $+10 \mathrm{mV}$ ) recorded from L5 PL-CP neurons following UV activation of caged glutamate in L2 of the PL cortex. G, Average of excitatory local circuit maps showing robust L2 input to PL-CP neurons. $\boldsymbol{H}$, Average of excitatory inhibitory circuit maps showing robust inhibitory input to PL-CP neurons following activation of both L2 and L5. I, Coinjection of AAV-ChR2-YFP and CTB-AlexaFluor 647 (cholera toxin $\beta$-subunits conjugated with AlexaFluor 647) into the BLA. J, Experimental paradigm for comparing monosynaptic input to retrogradely labeled L2 PL-CA and L2 IL-CA neurons during wide-field activation of ChR2 + BLA axons via blue LED stimulation. $K$, Examples of monosynaptic EPSCs for a L2 IL-CA neuron (gray trace) and a L2 PL-CA neuron (black trace) in the same slice following blue LED stimulation (stim) of ChR2 + BLA axons. $\boldsymbol{K}$, Inset, Action potential firing in response to blue LED stimulation recorded in cell-attached mode from a L2 PL-CA neuron. Scale bars: $5 \mathrm{mV}, 20 \mathrm{~ms}$. $\boldsymbol{L}$, Paired comparison of EPSC values for L2 IL-CA and 
continued

L2 PL-CA neurons. $* p<0.05$; error bars $=$ SEM.

clamp configuration, we found that LED stimulation ( $3 \mathrm{~ms}$ ) of BLA axons could elicit firing of L2 PL-CA neurons (Fig. $3 K$, inset). Based on our local mapping results, this finding suggests that BLA input to PL-CP neurons may involve local processing through L2 CA neurons.

\section{Projection identity and laminar location of mPFC neurons determines strength of BLA monosynaptic input}

Preferential synaptic connectivity of the BLA onto specific L2 cell types in the MPFC has been shown previously (Little and Carter, 2013). In addition to L2, CA neurons are distributed in L3 and L5 of IL cortex (Ferreira et al., 2015). We hypothesized that cell-type-specific targeting of the BLA also occurred between CA and CP neurons in L5 of IL cortex. We injected AAV-ChR2-YFP into the BLA and used fluorescently distinct retrograde tracers to identify IL-CP and IL-CA neurons in the same slice (Fig. $4 A-C$ ). Performing sequential whole-cell recordings from pairs of neighboring L5 IL-CP and L3/5 IL-CA neurons (Fig. 4D), we found that BLA inputs evoked significantly larger EPSCs (mean of peak $\pm 1 \mathrm{~ms}$ ) in L5 IL-CP neurons (458 \pm $156 \mathrm{pA})$ compared with L3/5 IL-CA neurons $(67.0 \pm 35$ $\mathrm{pA} ; n=7$ pairs $/ 8$ mice; $p=0.03^{\mathrm{h}}$; Student's paired $t$ test; Fig. 4E,F). These data support our hypothesis by showing that the BLA preferentially targets $L 5 \mathrm{CP}$ neurons over L3/5 CA neurons in IL cortex.

Because CA neurons are distributed in $\mathrm{L} 2$ and $\mathrm{L} 3 / 5$ in IL cortex (Fig. 4C) and because the labeling pattern of BLA axons in mPFC showed robust expression in L5 compared with L2 in IL cortex (Fig. 1), we hypothesized that BLA input would be stronger in L3/5 IL-CA neurons compared with L2 IL-CA neurons (Fig. 4G). Again in the presence of polysynaptic blockers, sequential whole-cell recordings revealed that BLA inputs evoked significantly larger EPSCs (mean of peak $\pm 1 \mathrm{~ms}$ ) in L3/5 IL-CA neurons $(210 \pm 44 \mathrm{pA})$ compared with L2 IL-CA neurons $\left(60.5 \pm 12 \mathrm{pA} ; n=8\right.$ pairs/7 mice; $p=0.005^{i}$; Fig. $\left.4 H, I\right)$. These data show that the strength of BLA input to CA neurons in IL cortex depends on laminar location of the soma.

\section{Discussion}

Our findings reveal unknown details regarding synaptic targeting of the BLA onto pyramidal neurons in the $\mathrm{mPFC}$ relevant in the endogenous analgesic network and in neural pathways relevant in fear conditioning. We combined retrograde tracing, brain-slice electrophysiology, and viral optogenetics to delineate the long-range targeting of the BLA onto defined CP and CA neurons in the mouse PL and IL cortex. We show that the BLA preferentially targets L5 CP neurons in IL cortex over the PL cortex. We also show that monosynaptic inputs originating in the BLA are stronger to L5 CP neurons than neighboring L3/5 CA neurons in IL cortex. This type of preferential connectivity of BLA input has been demon- strated in L2 of the mouse mPFC (Little and Carter, 2013). However, this previous study showed that excitatory inputs from the BLA were stronger to L2 CA neurons compared to neighboring neurons projecting to the contralateral $\mathrm{mPFC}$. Our results complement these findings and also demonstrate that the BLA preferentially and monosynaptically targets pyramidal neurons in L5 of IL cortex based on subcerebral projection target.

Polysynaptic excitatory responses in L5 PL-CP neurons following stimulation of BLA projections indicated activation of local cortical pathways in PL cortex. Dissection of local circuit pathways has uncovered a strong $L 2 / 3 \rightarrow L 5$ projection across multiple cortical areas (Kampa et al., 2006; Weiler et al., 2008; Anderson et al., 2010; Hooks et al., 2011; Ferreira et al., 2015). Using laser-scanning photostimulation of caged glutamate, we show that L5 PL-CP neurons receive strong descending input from $L 2$. Given that the preferential targeting of BLA to L2 PL-CA neurons can induce action potential firing, we speculate that polysynaptic activity recorded in PL-CP neurons during excitation of BLA axons may be due in part to activation of a L2 CA $\rightarrow$ L5 CP pathway (Fig. 5). Paired recordings of retrogradely labeled $\mathrm{L} 2 \mathrm{CA}$ and L5 CP will be necessary to confirm this speculation and will be one focus of future studies. Additionally, the interactions of the $\mathrm{PL}$ and IL cortex remain unclear. Optogenetic activation of IL pyramidal neurons can inhibit PL pyramidal neurons (Ji and Neugebauer, 2012). However, the laminar pathways of this interaction are unknown. It is conceivable that activation of L2 neurons in one cortical region (eg, L2 PL-CA) evokes feedforward inhibition of L5 neurons in the neighboring cortical region (eg, L5 IL-CP neurons). Detailed local circuit mapping is necessary to confirm this type of intercortical interaction.

Comprehensive retrograde tracing experiments suggest that the rat mPFC is divided into functionally overlapping yet distinct dorsal and ventral domains containing strategically organized pyramidal neurons that project to specific sets of other subcortical structures including the parabrachial nucleus, rostral ventral medulla, hypothalamus, and spinal cord (Gabbott et al., 2005). Given that these projection neurons are distributed primarily in L5 of both PL and IL cortex (Gabbott et al., 2005), our data suggest that the BLA will preferentially target those neurons in L5 of IL over PL cortex. However, targeting of BLA axons to apical dendrites of L5 pyramidal neurons in PL cortex still must be explored. Additional studies also provide evidence that functional differences occur dorsoventrally in the mPFC (Giustino and Maren, 2015). Our data clearly show that the BLA targets CP neurons, CA neurons, and inhibitory interneurons [likely parvalbuminpositive $(\mathrm{PV}+)$; Gabbott et al., 2006] in both PL and IL. However, our findings suggest that differences in laminar targeting and strength of inputs to these cortical neurons 
A

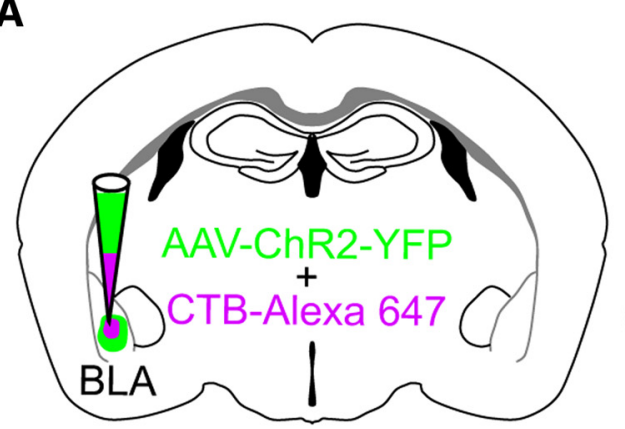

Bregma - $1.34 \mathrm{~mm}$
B

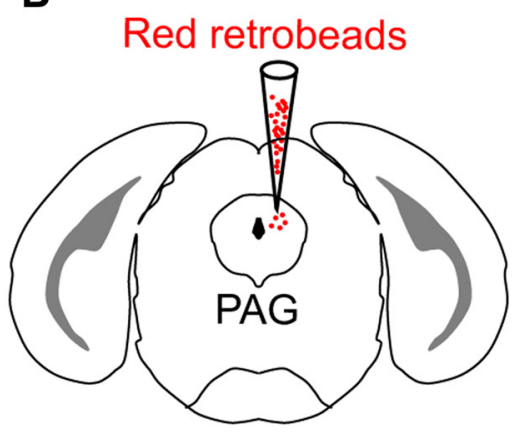

Bregma - $4.3 \mathrm{~mm}$

C

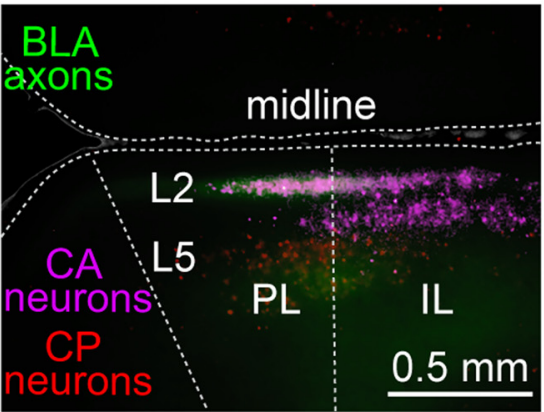

D

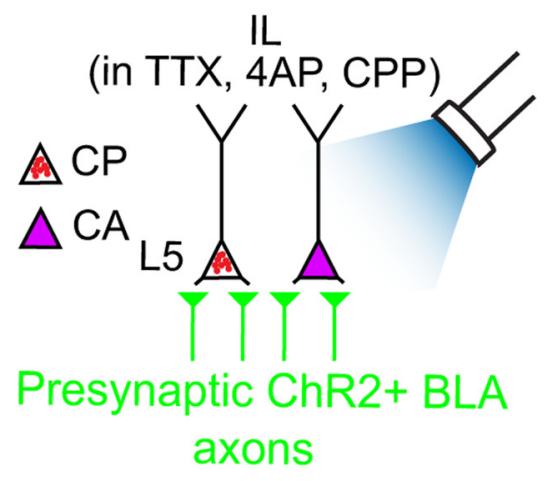

G

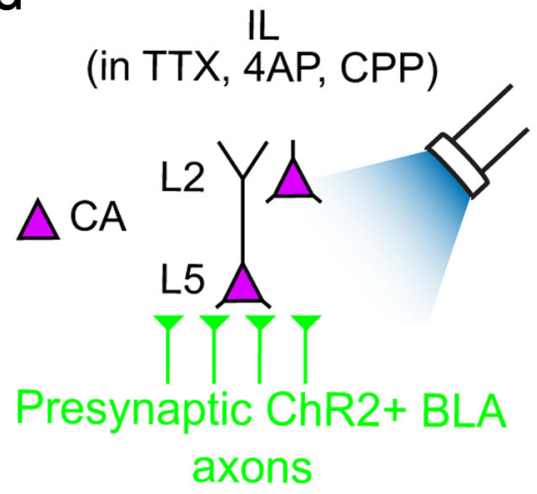

E

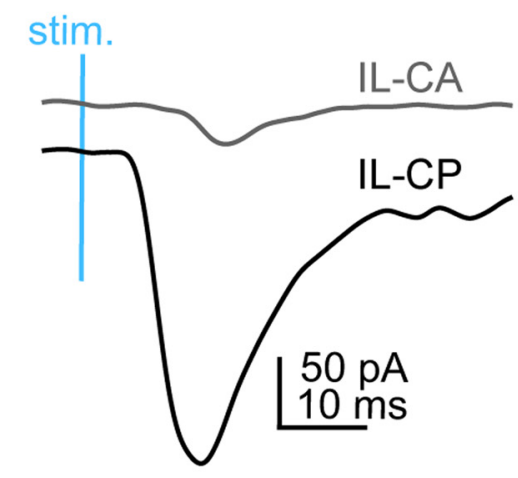

H

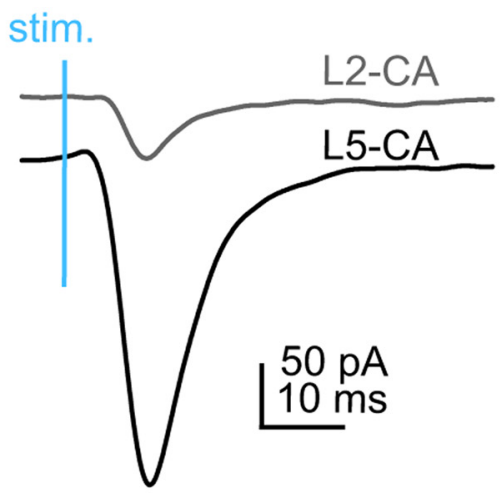

F

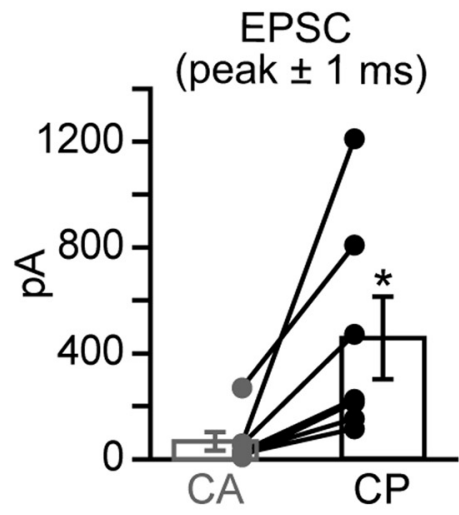

I

\section{EPSC}

$($ peak $\pm 1 \mathrm{~ms})$

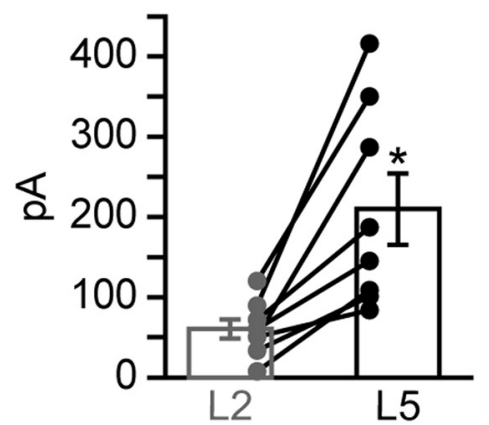

Figure 4. Targeting of BLA axons in the IL cortex is projection and laminar specific. $\boldsymbol{A}$, Coinjection of AAV-ChR2-YFP and CTB-AlexaFluor 647 into the BLA. B, Injection of red Retrobeads IX into the PAG. $\boldsymbol{C}$, Epifluorescence image overlay of the mPFC showing regional and laminar distribution of CA neurons (purple), BLA axons (green), and CP neurons (red) in the PL and IL cortical regions of the mPFC. $\boldsymbol{D}$, Experimental paradigm for comparing monosynaptic input to L5 CP and CA neurons in IL during wide-field activation of ChR2+ BLA axons via blue LED stimulation. $\boldsymbol{E}$, Examples of monosynaptic EPSCs for a L5 IL-CP neuron (gray trace) and a L5 IL-CA neuron (black trace) in the same slice following blue LED stimulation (stim) of ChR2 + BLA axons. $\boldsymbol{F}$, Paired comparison of monosynaptic EPSC values for L5 IL-CA and L5 IL-CP neurons. G, Experimental paradigm for comparing monosynaptic input to retrogradely labeled L2 and L5 CA neurons in IL during wide-field activation of ChR2 + BLA axons via blue LED stimulation. $\boldsymbol{H}$, Examples of monosynaptic EPSCs for a L2 IL-CA neuron (black trace) and a L5 IL-CA neuron (gray trace) in the same slice following blue LED stimulation (stim.) of ChR2+ BLA axons. I, Paired comparison of monosynaptic EPSC values for L2 IL-CA and L5 IL-CA neurons. $*=p<0.05$; error bars $=$ SEM.

play a significant role in the functional dichotomy between these $\mathrm{MPFC}$ regions. We speculate that this holds true for other L2 and L5 projection neurons and inhibitory in- terneurons spanning both PL and IL. How these inputs are affected in nociceptive/antinociceptive or fear expression/ extinction context requires further investigation. 


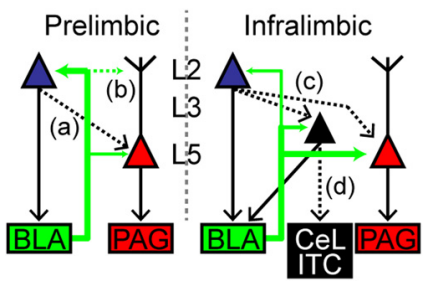

Figure 5. Working circuit diagram for BLA targeting of CP and CA neurons in PL and IL cortex. In PL cortex, the BLA sends robust projections to $\mathrm{L} 2 \mathrm{PL}-\mathrm{CA}$ and weaker projections $\mathrm{L} 5$ PL-CP neurons. A local L2 CA $\rightarrow$ L5 CP pathway (a) and targeting of the BLA to apical dendrites of L5 PL-CP neurons (b) remain unresolved. In IL cortex, the BLA preferentially targets L5 IL-CP neurons over L3/5 IL-CA neurons. The BLA also preferentially targets L3/5 IL-CA neurons over L2 IL-CA neurons. Local L2 $\mathrm{CA} \rightarrow \mathrm{L} 5 \mathrm{CP}$ and $\mathrm{L} 2 \mathrm{CA} \rightarrow \mathrm{L} 3 / 5 \mathrm{CA}$ pathways $(\boldsymbol{c})$ and targeting of L3/5 CA neurons specifically to the central lateral amygdala $(\mathrm{CeL})$ and intercalated (ITC) regions (d) remain unresolved. Thickness of green arrows $=$ relative strength of connection; dashed lines $=$ unresolved connections.

The connectivity of ascending BLA inputs to L5 CP neurons in the MPFC has functional implications related to nociception. Stimulation of the MPFC can produce analgesia in rats (Hardy, 1985) and can alter the firing rate of PAG neurons responsive to noxious input (Hardy and Haigler, 1985). Ascending nociception activates the amygdala via the parabrachial area (Bernard et al., 1996; Gauriau and Bernard, 2002) and the thalamus (Lanuza et al., 2008). Further, lesions in the amygdala disrupt the conditional hypoalgesia that is driven by endogenous anti-nociceptive circuitry during a Pavlovian conditional stimulus (Helmstetter, 1992; Helmstetter and Bellgowan, 1993). Based on these findings, we speculate that BLA targeting of L5 CP neurons is a critical component of the BLA driven activity within the endogenous analgesic network recruited during painful stimuli and fear-conditioned analgesia. Additionally, persistent pain alters the BLAmPFC pathway. In a rat model of arthritic pain, increased plasticity in the BLA contributes to both sensory and affective pain behavior and to increased polysynaptic inhibition of L5 neurons in PL cortex (Ji et al., 2010). Anatomical studies show that the BLA targets PV+ inhibitory neurons in rat $\mathrm{mPFC}$, which likely contribute to "feedforward" inhibition of pyramidal neurons (Gabbott et al., 2006). Our results indicate that increased polysynaptic inhibition of $L 5$ neurons in PL cortex would decrease output to the PAG potentially diminishing the suppression of ascending nociceptive signaling. Studies confirm that enhancing neurotransmission primarily in the $\mathrm{PL}$ cortex reduces neuropathic pain behavior (Millecamps et al., 2007; Lee et al., 2015), which may in part involve increased output to the PAG and the BLA.

In addition to altering the dynamics of cortical pain control, differential targeting of the PL and IL cortex by the BLA have implications in how MPFC networks affect fear conditioning. It has been shown that PL stimulation enhances fear expression and IL activity is critical for fear extinction (Milad and Quirk, 2002; Vidal-Gonzalez et al., 2006; Quirk and Mueller, 2008; Bukalo et al., 2015). Two distinct pathways originating in the BLA play a major role in the balance of activity between the PL and the IL during fear expression and fear extinction, respectively (Senn et al., 2014). Our findings indicate that increased BLA input to the IL detected during fear extinction (Senn et al., 2014) directly affects the activity of L5 IL-CP neurons, which target the ventral PAG (Ferreira et al., 2015). There is evidence suggesting that $\mathrm{MPFC}$ activity triggers opioid release within the PAG (Tracey and Mantyh, 2007; Wagner et al., 2007). Therefore, we suspect that enhanced signaling of the BLA to the IL will directly increase the activity of IL-CP neurons potentially leading to opioid release in the ventral PAG which is essential for fear extinction (McNally et al., 2004; McNally et al., 2011).

We also show that the BLA preferentially targets CP neurons over CA neurons in L5 of IL cortex. Nonetheless, the BLA does directly excite CA neurons in IL cortex preferentially targeting CA neurons in L3/5 over L2. Previous studies propose that $\mathrm{CA}$ neurons in IL cortex target and activate the GABAergic cells (ITC) in the amygdala, which are involved in the retrieval of fear extinction memories (Quirk et al., 2003; Likhtik et al., 2008; Amir et al., 2011). However, new evidence suggests that IL activation of the ITC occurs indirectly through the stimulation of the BLA (Strobel et al., 2015). Another study showed that in addition to targeting the BLA and ITC, IL cortex sends robust projections to the central lateral amygdala (CeL; Pinard et al., 2012). The CeL inhibits output neurons of central medial amygdala (CeM; Ciocchi et al., 2010) including neurons projecting to the PAG (Haubensak et al., 2010), which are important for initiating fear responses (Paré et al., 2004). Indeed, fear extinction involves ILmediated inhibition of CeM output (Amano et al., 2010), which may be driven via activation of ITC and/or CeL pathways.

A subpopulation of neurons projecting to the perirhinal cortex (PRC) is found in both L2/3 and L5 of the rat frontal cortex (Hirai et al., 2012). However, it was found that these PRC-projecting L2/3 and L5 neurons displayed different firing properties and targeted distinct areas within the PRC (Hirai et al., 2012). This suggests that subsets of cortical neurons projecting to different subregions within cortical and subcortical structures have distinct laminar and electrophysiological profiles. In mouse mPFC, L2 IL-CA and L3/5 IL-CA neurons have distinct subthreshold properties (Ferreira et al., 2015) and therefore may target specific subregions within the amygdala. It has been shown that L2 IL-CA and L3/5 IL-CA are intrinsically different (Ferreira et al., 2015) and therefore may have distinct projection targets within the amygdala. We speculate that L2 IL-CA neurons may project mainly to the BLA, whereas L3/5 IL-CA neurons target the CeL and ITC (Fig. 5). It is conceivable that input from L2 IL-CA neurons to BLA would inhibit CeM output via activation of ITC (Amano et al., 2010) or through excitation of GABAergic CeL neurons (Tye et al., 2011). However, it is also possible the L3/5 IL-CA neurons target PKC- $\delta+$ CeL neurons which inhibit CeM output to the PAG (Haubensak et al., 2010) thereby decreasing fear response. Other evidence shows that PKC- $\delta-$ CeL neurons send direct inhibitory 
input to the PAG and that synaptic activity of these neurons is increased by fear conditioning (Penzo et al., 2014). Because PKC- $\delta+$ neurons inhibit PKC- $\delta$ - (Haubensak et al., 2010) activation of PKC- $\delta+$ neurons by IL inputs may decrease PKC- $\delta-$ driven inhibition of the PAG. Therefore, the increased BLA input to the IL cortex observed during fear extinction (Senn et al., 2014) likely involves eliciting output of L5 IL-CP neurons, which directly drive activity of the PAG in combination with eliciting output of L2 and L3/5 IL-CA neurons, which indirectly disinhibits the PAG via CeL and ITC pathways (Fig. 5). An intriguing future direction will involve experiments testing the local connectivity between $\mathrm{CP}$ and CA neurons in IL cortex by using paired recordings and/or optogenetic techniques (Fig. 5).

The PL cortex is critical for fear expression and the reduction of extinction retrieval (Vidal-Gonzalez et al., 2006; Corcoran and Quirk, 2007; Burgos-Robles et al., 2009; Sotres-Bayon et al., 2012). We found that the BLA evokes stronger excitatory input to L2 CA neurons in PL over IL cortex. Output of the PL to the amygdala (ie, L2 PL-CA neurons) consists of excitatory projections (Brinley-Reed et al., 1995) targeting the BLA (Vertes, 2004; Gabbott et al., 2005). The BLA sends excitatory input to the CeL (Samson et al., 2005), which disinhibits CeM output and leads to conditioned fear responses (Ciocchi et al., 2010). Yet, a more recent study shows that the BLA-CeL pathway reduces CeM output leading to anxiolytic behavioral effects (Tye et al., 2011). However, this same study showed that a subpopulation of BLA neurons can directly excite the $\mathrm{CeM}$, which contributes to increased anxiety behavior (Tye et al., 2011). It is possible that BLA neurons responsible for increased activation of the PL cortex during states of high fear (Senn et al., 2014) concurrently excite CeM neurons. Moreover, BLA targeting of PL cortex involves a strong and excitatory reciprocal signal back from L2 neurons, which may target BLA neurons responsible for direct enhancement of CeM output. In addition to sending input back to the BLA, it is likely that L2 PL-CA neurons also alter output to the PAG through local descending connections onto L5 PL-CP neurons (Fig. 5). This level of local processing for coordinating descending input to the BLA and PAG is a possible mechanism that distinguishes function of PL and IL cortex.

Collectively, this study shows that the BLA differentially targets $\mathrm{PL}$ and IL cortical output to the PAG and amygdala (Fig. 5). Because the PAG and amygdala are subcortical structures involved in regulating multiple physiological responses, most notably pain, anxiety, and autonomic regulation, we anticipate our findings will offer new insight into differential roles for PL and IL cortex in pain and anxiety disorders.

\section{References}

Amano T, Unal CT, Paré D (2010) Synaptic correlates of fear extinction in the amygdala. Nat Neurosci 13:489-494. CrossRef Medline Amir A, Amano T, Pare D (2011) Physiological identification and infralimbic responsiveness of rat intercalated amygdala neurons. $J$ Neurophysiol 105:3054-3066. CrossRef Medline
Anderson CT, Sheets PL, Kiritani T, Shepherd GM (2010) Sublayerspecific microcircuits of corticospinal and corticostriatal neurons in motor cortex. Nat Neurosci 13:739-744. CrossRef Medline

Basbaum Al, Fields HL (1978) Endogenous pain control mechanisms: review and hypothesis. Ann Neurol 4:451-462. CrossRef Medline

Behbehani MM (1995) Functional characteristics of the midbrain periaqueductal gray. Prog Neurobiol 46:575-605. Medline

Bernard JF, Bester H, Besson JM (1996) Involvement of the spinoparabrachio -amygdaloid and -hypothalamic pathways in the autonomic and affective emotional aspects of pain. Prog Brain Res 107:243-255. Medline

Berretta S, Pantazopoulos H, Caldera M, Pantazopoulos P, Pare D (2005) Infralimbic cortex activation increases c-Fos expression in intercalated neurons of the amygdala. Neuroscience 132:943-953. CrossRef Medline

Brinley-Reed M, Mascagni F, McDonald AJ (1995) Synaptology of prefrontal cortical projections to the basolateral amygdala: an electron microscopic study in the rat. Neurosci Lett 202:45-48. Medline

Bukalo O, Pinard CR, Silverstein S, Brehm C, Hartley ND, Whittle N, Colacicco G, Busch E, Patel S, Singewald N, Holmes A (2015) Prefrontal inputs to the amygdala instruct fear extinction memory formation. Sci Adv 1. CrossRef Medline

Burgos-Robles A, Vidal-Gonzalez I, Quirk GJ (2009) Sustained conditioned responses in prelimbic prefrontal neurons are correlated with fear expression and extinction failure. J Neurosci 29:84748482. CrossRef Medline

Chang $\mathrm{CH}$, Maren S (2011) Medial prefrontal cortex activation facilitates re-extinction of fear in rats. Learn Mem 18:221-225. CrossRef Medline

Ciocchi S, Herry C, Grenier F, Wolff SB, Letzkus JJ, Vlachos I, Ehrlich I, Sprengel R, Deisseroth K, Stadler MB, Müller C, Luthi A (2010) Encoding of conditioned fear in central amygdala inhibitory circuits. Nature 468:277-282. CrossRef Medline

Corcoran KA, Quirk GJ (2007) Activity in prelimbic cortex is necessary for the expression of learned, but not innate, fears. J Neurosci 27:840-844. CrossRef Medline

Do-Monte FH, Manzano-Nieves G, Quiñones-Laracuente K, RamosMedina L, Quirk GJ (2015) Revisiting the role of infralimbic cortex in fear extinction with optogenetics. J Neurosci 35:3607-3615. CrossRef Medline

Faul F, Erdfelder E, Lang AG, Buchner A (2007) G*Power 3: a flexible statistical power analysis program for the social, behavioral, and biomedical sciences. Behav Res Methods, 39:175-191. CrossRef

Ferreira AN, Yousuf H, Dalton S, Sheets PL (2015) Highly differentiated cellular and circuit properties of infralimbic pyramidal neurons projecting to the periaqueductal gray and amygdala. Front Cell Neurosci 9:161. CrossRef Medline

Fitzgerald PJ, Whittle N, Flynn SM, Graybeal C, Pinard CR, GunduzCinar O, Kravitz AV, Singewald N, Holmes A (2014) Prefrontal single-unit firing associated with deficient extinction in mice. Neurobiol Learn Mem 113:69-81. CrossRef Medline

Gabbott PL, Warner TA, Busby SJ (2006) Amygdala input monosynaptically innervates parvalbumin immunoreactive local circuit neurons in rat medial prefrontal cortex. Neuroscience 139:1039-1048. CrossRef Medline

Gabbott PL, Warner TA, Jays PR, Salway P, Busby SJ (2005) Prefrontal cortex in the rat: projections to subcortical autonomic, motor, and limbic centers. J Comp Neurol 492:145-177. CrossRef Medline

Gauriau C, Bernard JF (2002) Pain pathways and parabrachial circuits in the rat. Exp Physiol 87:251-258. Medline

Giustino TF, Maren S (2015) The role of the medial prefrontal cortex in the conditioning and extinction of fear. Front Behav Neurosci 9:298. CrossRef Medline

Hardy SG (1985) Analgesia elicited by prefrontal stimulation. Brain Res 339:281-284. Medline 
Hardy SG, Haigler HJ (1985) Prefrontal influences upon the midbrain: a possible route for pain modulation. Brain Res 339:285-293. Medline

Haubensak W, Kunwar PS, Cai H, Ciocchi S, Wall NR, Ponnusamy R, Biag J, Dong HW, Deisseroth K, Callaway EM, Fanselow MS, Lüthi A, Anderson DJ (2010) Genetic dissection of an amygdala microcircuit that gates conditioned fear. Nature 468:270-276. CrossRef Medline

Helmstetter FJ (1992) The amygdala is essential for the expression of conditional hypoalgesia. Behav Neurosci 106:518-528. Medline

Helmstetter FJ, Bellgowan PS (1993) Lesions of the amygdala block conditional hypoalgesia on the tail flick test. Brain Res 612:253257. Medline

Hirai Y, Morishima M, Karube F, Kawaguchi Y (2012) Specialized cortical subnetworks differentially connect frontal cortex to parahippocampal areas. J Neurosci 32:1898-1913. CrossRef Medline

Holmes A, Fitzgerald PJ, MacPherson KP, DeBrouse L, Colacicco G, Flynn SM, Masneuf S, Pleil KE, Li C, Marcinkiewcz CA, Kash TL, Gunduz-Cinar O, Camp M (2012) Chronic alcohol remodels prefrontal neurons and disrupts NMDAR-mediated fear extinction encoding. Nat Neurosci 15:1359-1361. CrossRef Medline

Hooks BM, Hires SA, Zhang YX, Huber D, Petreanu L, Svoboda K, Shepherd GM (2011) Laminar analysis of excitatory local circuits in vibrissal motor and sensory cortical areas. PLoS Biol 9:e1000572. CrossRef Medline

Hurley KM, Herbert H, Moga MM, Saper CB (1991) Efferent projections of the infralimbic cortex of the rat. J Comp Neurol 308:249276. CrossRef Medline

Ishikawa A, Nakamura S (2003) Convergence and interaction of hippocampal and amygdalar projections within the prefrontal cortex in the rat. J Neurosci 23:9987-9995. Medline

$\mathrm{Ji} \mathrm{G}$, Neugebauer V (2012) Modulation of medial prefrontal cortical activity using in vivo recordings and optogenetics. Mol Brain 5:36. CrossRef Medline

Ji G, Sun H, Fu Y, Li Z, Pais-Vieira M, Galhardo V, Neugebauer V (2010) Cognitive impairment in pain through amygdala-driven prefrontal cortical deactivation. J Neurosci 30:5451-5464. CrossRef Medline

Kampa BM, Letzkus JJ, Stuart GJ (2006) Cortical feed-forward networks for binding different streams of sensory information. Nat Neurosci 9:1472-1473. CrossRef Medline

Lanuza E, Moncho-Bogani J, Ledoux JE (2008) Unconditioned stimulus pathways to the amygdala: effects of lesions of the posterior intralaminar thalamus on foot-shock-induced c-Fos expression in the subdivisions of the lateral amygdala. Neuroscience 155:959968. CrossRef Medline

Laurent V, Westbrook RF (2009) Inactivation of the infralimbic but not the prelimbic cortex impairs consolidation and retrieval of fear extinction. Learn Mem 16:520-529. CrossRef Medline

Lee M, Manders TR, Eberle SE, Su C, D'Amour J, Yang R, Lin HY, Deisseroth K, Froemke RC, Wang J (2015) Activation of corticostriatal circuitry relieves chronic neuropathic pain. J Neurosci 35: 5247-5259. CrossRef Medline

Likhtik E, Popa D, Apergis-Schoute J, Fidacaro GA, Paré D (2008) Amygdala intercalated neurons are required for expression of fear extinction. Nature 454:642-645. CrossRef Medline

Little JP, Carter AG (2012) Subcellular synaptic connectivity of layer 2 pyramidal neurons in the medial prefrontal cortex. J Neurosci 32:12808-12819. CrossRef Medline

Little JP, Carter AG (2013) Synaptic mechanisms underlying strong reciprocal connectivity between the medial prefrontal cortex and basolateral amygdala. J Neurosci 33:15333-15342. CrossRef Medline

McDonald AJ (1998) Cortical pathways to the mammalian amygdala. Prog Neurobiol 55:257-332. Medline

McDonald AJ, Mascagni F, Guo L (1996) Projections of the medial and lateral prefrontal cortices to the amygdala: a Phaseolus vulgaris leucoagglutinin study in the rat. Neuroscience 71:55-75. CrossRef Medline
McNally GP, Pigg M, Weidemann G (2004) Opioid receptors in the midbrain periaqueductal gray regulate extinction of pavlovian fear conditioning. J Neurosci 24:6912-6919. CrossRef Medline

McNally GP, Johansen JP, Blair HT (2011) Placing prediction into the fear circuit. Trends Neurosci 34:283-292. CrossRef Medline

Milad MR, Quirk GJ (2002) Neurons in medial prefrontal cortex signal memory for fear extinction. Nature 420:70-74. CrossRef Medline

Millecamps M, Centeno MV, Berra HH, Rudick CN, Lavarello S, Tkatch T, Apkarian AV (2007) D-cycloserine reduces neuropathic pain behavior through limbic NMDA-mediated circuitry. Pain 132: 108-123. CrossRef Medline

Orozco-Cabal L, Pollandt S, Liu J, Vergara L, Shinnick-Gallagher P, Gallagher JP (2006) A novel rat medial prefrontal cortical slice preparation to investigate synaptic transmission from amygdala to layer V prelimbic pyramidal neurons. J Neurosci methods 151:148158. CrossRef

Paré D, Quirk GJ, Ledoux JE (2004) New vistas on amygdala networks in conditioned fear. J Neurophysiol 92:1-9. CrossRef Medline

Penzo MA, Robert V, Li B (2014) Fear conditioning potentiates synaptic transmission onto long-range projection neurons in the lateral subdivision of central amygdala. J Neurosci 34:2432-2437. CrossRef Medline

Peters J, Kalivas PW, Quirk GJ (2009) Extinction circuits for fear and addiction overlap in prefrontal cortex. Learn Mem 16:279-288. CrossRef Medline

Petreanu L, Huber D, Sobczyk A, Svoboda K (2007) Channelrhodopsin-2-assisted circuit mapping of long-range callosal projections. Nat Neurosci 10:663-668. CrossRef Medline

Petreanu L, Mao T, Sternson SM, Svoboda K (2009) The subcellular organization of neocortical excitatory connections. Nature 457: 1142-1145. CrossRef Medline

Pinard CR, Mascagni F, McDonald AJ (2012) Medial prefrontal cortical innervation of the intercalated nuclear region of the amygdala. Neuroscience 205:112-124. CrossRef Medline

Quirk GJ, Mueller D (2008) Neural mechanisms of extinction learning and retrieval. Neuropsychopharmacology 33:56-72. CrossRef

Quirk GJ, Likhtik E, Pelletier JG, Paré D (2003) Stimulation of medial prefrontal cortex decreases the responsiveness of central amygdala output neurons. J Neurosci 23:8800-8807. Medline

Samson RD, Duvarci S, Paé D (2005) Synaptic plasticity in the central nucleus of the amygdala. Rev Neurosci 16:287-302. Medline

Schubert D, Staiger JF, Cho N, Kotter R, Zilles K, Luhmann HJ (2001) Layer-specific intracolumnar and transcolumnar functional connectivity of layer $\mathrm{V}$ pyramidal cells in rat barrel cortex. J Neurosci 21:3580-3592. Medline

Senn V, Wolff SB, Herry C, Grenier F, Ehrlich I, Gründemann J, Fadok JP, Müller C, Letzkus JJ, Lüthi A (2014) Long-range connectivity defines behavioral specificity of amygdala neurons. Neuron 81: 428-437. CrossRef Medline

Sheets PL, Suter BA, Kiritani T, Chan CS, Surmeier DJ, Shepherd GM (2011) Corticospinal-specific HCN expression in mouse motor cortex: I(h)-dependent synaptic integration as a candidate microcircuit mechanism involved in motor control. J Neurophysiol 106: 2216-2231. CrossRef Medline

Sierra-Mercado D, Padilla-Coreano N, Quirk GJ (2011) Dissociable roles of prelimbic and infralimbic cortices, ventral hippocampus, and basolateral amygdala in the expression and extinction of conditioned fear. Neuropsychopharmacology 36:529-538. CrossRef

Sierra-Mercado D Jr, Corcoran KA, Lebrón-Milad K, Quirk GJ (2006) Inactivation of the ventromedial prefrontal cortex reduces expression of conditioned fear and impairs subsequent recall of extinction. Eur J Neurosci 24:1751-1758. CrossRef

Sotres-Bayon F, Sierra-Mercado D, Pardilla-Delgado E, Quirk GJ (2012) Gating of fear in prelimbic cortex by hippocampal and amygdala inputs. Neuron 76:804-812. CrossRef Medline

Strobel C, Marek R, Gooch HM, Sullivan RK, Sah P (2015) Prefrontal and auditory input to intercalated neurons of the amygdala. Cell Rep 10:1435-1442. 
Suter BA, O'Connor T, lyer V, Petreanu LT, Hooks BM, Kiritani T, Svoboda K, Shepherd GM (2010) Ephus: multipurpose data acquisition software for neuroscience experiments. Front Neural Circuits 4:100. CrossRef Medline

Tracey I, Mantyh PW (2007) The cerebral signature for pain perception and its modulation. Neuron 55:377-391. CrossRef Medline

Tye KM, Prakash R, Kim SY, Fenno LE, Grosenick L, Zarabi H, Thompson KR, Gradinaru V, Ramakrishnan C, Deisseroth K (2011) Amygdala circuitry mediating reversible and bidirectional control of anxiety. Nature 471:358-362. CrossRef Medline

Vertes RP (2004) Differential projections of the infralimbic and prelimbic cortex in the rat. Synapse 51:32-58. CrossRef Medline
Vidal-Gonzalez I, Vidal-Gonzalez B, Rauch SL, Quirk GJ (2006) Microstimulation reveals opposing influences of prelimbic and infralimbic cortex on the expression of conditioned fear. Learn Mem 13:728-733. CrossRef Medline

Wagner KJ, Sprenger T, Kochs EF, Tölle TR, Valet M, Willoch F (2007) Imaging human cerebral pain modulation by dosedependent opioid analgesia: a positron emission tomography activation study using remifentanil. Anesthesiology 106:548-556. Medline

Weiler N, Wood L, Yu J, Solla SA, Shepherd GM (2008) Top-down laminar organization of the excitatory network in motor cortex. Nat Neurosci 11:360-366. CrossRef Medline 